\title{
In other words
}

\section{DARIA DAYTER AND SOFIA RÜDIGER}

\author{
'The language of attraction' used by pick-up artists
}

\section{Introduction}

The idea that speaking in a certain way can make people do things - persuasion on steroids, so to say - is understandably fascinating. This holy grail of communication studies is sought after by 'professional persuaders', politicians and copywriters, but also in non-professional situations. One example of wishful thinking of what is possible when it comes to the power of language is the Pick-up Artist (PUA) paradigm. PUAs are a community of self-designated or aspiring seduction experts; and it should come as no surprise that most members are men. While it is possible for PUAs to meet face-to-face, for example, at workshops organized by the so-called gurus (at no little cost to the students of pick-up), much of the interaction between the members takes place in PUA Internet forums and similar online venues.

PUAs claim to rely on linguistic techniques and neuro-linguistic programming (NLP) to achieve their 'speed seduction' objective. As reported by Denes (2011: 418), many PUA techniques, the so-called 'seduction scripts', rely on 'misappropriating science' to cast interaction with the opposite sex as something that can be taken apart like a Lego puzzle, and controlled. The idea is that if you use certain phrases in the right way, women simply cannot help but like you.

The PUA movement undoubtedly uses effective persuasion techniques and therefore is very interesting for linguistic analysis. However, we beg to differ. It is second-level persuasion, i.e. convincing PUA adepts that the system works, not first-level persuasion, i.e. attracting women. The interaction would go the same way whether PUA scripts were used or not, but the subsequent recasting of the situation as a success makes all the difference to the confidence of the users.

In this paper we examine one aspect of this 'conspiracy', i.e. the scientification of flirting, primarily through vocabulary. A common type of forum writing called 'field reports' supplies the data for the study of PUA meta-discourse since this is where community members discuss their flirting experiences. We ask how frequent the special PUA vocabulary is on thematic forums and exactly how this meta-discourse is made irresistible to the would-be members.

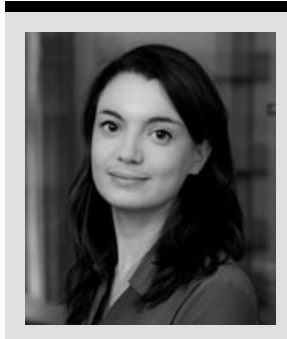

Hailing from Russia, DARIA DAYTER first graduated in translation and interpreting before studying linguistics in Bayreuth, Germany. She completed her PhD in English linguistics in Bayreuth in 2014, and subsequently published a monograph, 'Discursive self in microblogging. Speech acts, stories and self-praise' with John Benjamins. She is currently working on a postdoc project in corpus-based interpreting studies in Basel, Switzerland. Her research interests include corpus linguistics, conference interpreting, and computer-mediated communication.

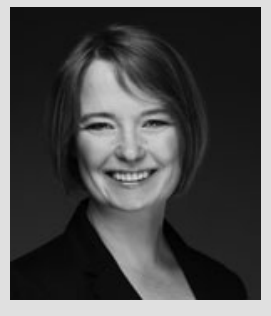

SOFIA RÜDIGER graduated with degrees in English studies and English linguistics from the University of Bayreuth in Germany. She completed her PhD on morpho-syntactic patterns by South Korean speakers of English in 2017 and is currently working as a postdoctoral research associate in Bayreuth. Her major research interests include computermediated communication, discourse analysis, World Englishes, and non-canonical syntax. The newest additions to her research agenda are the linguistics of food and persuasive language. 


\section{Make it look like science}

PUA gurus claim NLP as a scientific basis for their methodology. Whether NLP as an instrument affecting human behaviour has any validity is a whole separate debate, although in a nutshell, the answer is no. Wilson (2002: 446), in a collection on pseudoscience in psychology, defines NLP as an 'unvalidated therapeutic method that purports to "program" brain functioning through a variety of techniques, including mirroring the postures and nonverbal behaviours of clients'. Vrij and Lochun (1997) cite numerous empirical studies that had tried, and failed, to demonstrate any observable effect of NLP techniques in experimental or natural settings. Indeed, when watching two police officers interview a suspect, one of the authors remarked, 'My first impression was that both detectives were behaving strangely'. As it turned out later, the officers had been using the NLP mirroring technique. Not only did the whole situation look bizarre, the technique also did not appear to have any effect as the suspect remained silent (Vrij \& Lochun, 1997: 28).

But as we mentioned above, the selling point of the PUA brand is not what it is but what it seems. Therefore, it is predictable that the imitation of the scientific basis for PUA techniques, and especially one that has the word linguistic in it, should take place at the most salient level of language, i.e. lexis. Marked, pseudoscientific vocabulary constitutes a cornerstone of the PUA paradigm. In all the different text types represented on a PUA forum, i.e. introductions, field reports, tips and guides, 'find a wingman' sections, and the 'psychology' sections as such, special terminology is very much present. It flags the space clearly as something for the initiated, for those who possess a unique expertise that makes them different from non-PUA counterparts.

At the same time, since the terminology is largely based on either the semantic reanalysis of everyday English vocabulary, or appropriation of terms from military and business domains, it is transparent enough even for a complete novice. On the one hand, the PUA terminology creates an illusion of belonging to an exclusive club of NLP adepts, while on the other, it in fact is a very low entry threshold. In addition, the pseudoscientific flair invokes associations with such values as intelligence, education, and logical thinking, which creates an illusion of high status for those joining.

\section{PUA terms everywhere}

The most straightforward way to gauge the prominence of pseudoscientific vocabulary in PUA genres is to look at its frequency, and at the contexts in which a PUA term is chosen over an unmarked variant. To do this, we compiled a 24,000-word corpus of 'field reports' which are a sort of debriefing that PUAs post online to give a play-by-play account of their experiences with women or to ask for advice. The corpus contains 37 posts from Anglophone PUA forums that do not require registration to post or read the messages (for more details, see Rüdiger \& Dayter, 2017). To find all instances of PUA vocabulary, we analysed the corpus with the help of the freeware concordancer AntConc (Anthony, 2014) and a manually compiled wordlist (our PUA thesaurus). To evaluate the PUA vs. non-PUA word usage, we chose to focus on the talk about women. We manually identified all the tokens that designate women in the corpus, and compared the frequency of relatively unmarked items, such as woman, girl, chick with PUA terms, such as $H B$ [hot babe], target.

As expected, field reports are studded with special terminology. PUA-specific words make up $2.33 \%$ of the corpus (with 558 hits altogether for 194 different word types). To put this figure into perspective, all the word forms of such common verbs as to do, to go, to think, and to have cumulatively amount to almost the same share, $2.45 \%$. When compared with a reference corpus of non-PUA dating advice for men (compiled with posts from a general purpose online forum aimed at men), PUA terms are ranked high among the keywords (highlighted in bold font in Table 1) since they occupy nine positions in the top-20 list.

An even more striking profile emerges when we consider which words or expressions PUAs use to talk about women. On the whole, the data shows a predictable preference for the neutral, or almost condescending, girl/girls (61\%). But among the remaining $39 \%$, synonymous PUA terms, such as target, obstacle, $H B$ [hot babe], rotation, are well ahead of the unmarked woman/chick/lady. While the second group yields 45 hits (16.6\%), PUA terms are used in $22.5 \%$ of comparable contexts. This choice speaks to the priorities of the PUA community. It is not simply an overt justification of male privilege and objectification of women in the game-like frame of flirting (Glick \& Fiske, 1996), but the emphasis on the arcane in-group lingo that holds this community together.

\section{The origins of pseudoscientific PUA terminology}

As we have explained above, the PUAs' system does not have a genuine scientific basis. This 


\begin{tabular}{|lrll|}
\hline \multicolumn{4}{|l}{ Table 1: Keywords in the field reports vs. dating } \\
advice corpus & \multicolumn{1}{l|}{} & \\
\hline Rank & Hits & LL & Keyword \\
\hline $\mathbf{1}$ & $\mathbf{5 7}$ & $\mathbf{7 2 . 1 8 4}$ & field \\
\hline $\mathbf{2}$ & $\mathbf{5 5}$ & $\mathbf{6 9 . 4 1 5}$ & game \\
\hline 3 & 210 & 63.603 & you \\
\hline 4 & 353 & 56.026 & my \\
\hline 5 & 761 & 55.359 & the \\
\hline $\mathbf{6}$ & $\mathbf{3 2}$ & $\mathbf{4 5 . 4 3 7}$ & hb \\
\hline $\mathbf{7}$ & $\mathbf{3 1}$ & $\mathbf{4 4 . 0 1 7}$ & report \\
\hline 8 & 30 & 42.597 & lisa \\
\hline $\mathbf{9}$ & $\mathbf{2 7}$ & $\mathbf{3 8 . 3 3 7}$ & reports \\
\hline $\mathbf{1 0}$ & $\mathbf{3 4}$ & $\mathbf{3 1 . 5 1 3}$ & set \\
\hline 11 & 21 & 29.818 & misty \\
\hline $\mathbf{1 2}$ & $\mathbf{2 1}$ & $\mathbf{2 9 . 8 1 8}$ & target \\
\hline 13 & 33 & 26.922 & post \\
\hline 14 & 80 & 25.280 & they \\
\hline $\mathbf{1 5}$ & $\mathbf{1 6}$ & $\mathbf{2 2 . 7 1 8}$ & approaches \\
\hline 16 & 20 & 21.711 & lol \\
\hline $\mathbf{1 7}$ & $\mathbf{2 3}$ & $\mathbf{2 1 . 4 2 6}$ & open \\
\hline 18 & 15 & 21.298 & forum \\
\hline 19 & 14 & 19.879 & cab \\
\hline 20 & 14 & 19.879 & shaitan \\
\hline & & & \\
\hline & & & \\
\hline & & & \\
\hline
\end{tabular}

means that the pseudoscientific vocabulary had to be creatively compiled from other sources on the condition of surface similarity to hard science. In order to arrive at a pseudoscientific make-up, PUA vocabulary and discourse rely on appropriated use of quantification, abbreviations, Latinate and Greek roots, and part-of-speech conversion.

One of the key devices of the pick-up is to imagine a flirtatious encounter as a different activity, for instance, a military exercise or athletic training (Dayter \& Rüdiger, 2016). This re-imagining and re-contextualizing of one situation within the perspective of another situation is referred to as framing (see e.g. Kuypers, 2009). In the PUA community, framing is used to take off the pressure to succeed, since within the training frame, for example, a failed attempt is as valuable as a successful one. The choice of frame explains the source of many pseudo-terms in our PUA thesaurus. $32 \%$ of those terms come from sports,

$23.6 \%$ from the military, $9 \%$ from business, and $5 \%$ from science.

The military domain seems to be especially appealing to PUAs, probably because it implies being 'a real man' and is associated with attributes such as power, physical strength, and grit. Many field reports read almost like accounts of a military troupe approaching a group of insurgents with a mission in mind that is far from peaceful:

Due to the loud music and our physical positioning I wasn't able to engage the obstacle as much as the target. I was standing beside my target and did a few smaller attraction routines (Cold Reads and Teases) on her, while making little side comments to the obstacle.

Most strikingly, women are portrayed as adversaries who are either to be hunted or defeated. As we described in the previous section, the primary reference to a woman is a target; several women together are referred to as a set, which a PUA may engage or disengage. Engage usually means 'to talk', although the training scenario allows for a very broad definition of engagement, including 'looking at the set longingly from a corner of the room'. If a set includes people other than the target, the pickuper may try to isolate his target and then escalate the interaction. By invoking categorybound activities, core military vocabulary can be used to project behaviour expected from the women in target/prey roles. Phrases such as antislut defence or activate a slut-shield demonstrate how female behaviour is re-cast as a defence mechanism that needs to be overcome by the attacking force, i.e. the pick-up artist.

A slightly less aggressive frame that emphasizes repetition rather than conflict draws on sports training. The flirtatious encounter itself is famously described as a game. To succeed in the game, PUAs develop and practise specific sequences, akin to football formations (e.g. a 4-4-2 diamond). These may include cold reads, go caveman, or multithreading. The game frame is established via key vocabulary such as to open a set, to warm up, to close (number-close, kiss-close, etc. refer to different degrees of success with women). Interestingly, they appeal to the very specific frame of extreme sports, as opposed to more sedate games, by introducing problems typical of extreme sports scenarios such as choking or approach anxiety.

Finally, another high-prestige domain that pops up in PUA field reports is business. The business domain illustrates another main tenet of the PUA 
philosophy, namely, that flirting is all about relative status, i.e. value. Therefore, raising own value or lowering her value would both be successful strategies, while putting her into scarcity (a woman is presented as a resource that is in high demand) would make it more difficult for a PUA to 'close'.

All three domains are fair game in this genre, and a writer may freely mix his metaphors and talk about flirting as a battle, a match, and mergersand-acquisitions all in one report. For some common lexical items it is difficult to trace their derivation with any degree of certainty. They could be a result of metaphorical extension in any of the three domains, or idiosyncratic new formations that a guru has cooked up in a fit of inspiration. Among such key terms are the variations on kino 'physical contact with the woman', sarging 'engaging in the game, interacting with women, flirting', or the Hot Babe scale, which rates women from $H B 1$ to $H B 10$.

\section{Quantification: The numbers game}

The pseudoscientific frame of PUA is apparent in the free use of numbers in the field reports. Altogether, the data in our PUA field report corpus contains 93.16 numerals per 10,000 words (considering only Arabic numerals and not including spelled-out variants such as $t w o ; n=227)$, which means that on average, every field report includes six numbers. This unusually high number as compared to 80.77 numerals per 10,000 words in the reference corpus can be traced back to different functions of using numerals, which ultimately serve the scientification of the PUA approach.

In the field reports, numerals are employed to give performance stats (e.g. 'I have done 40 total approaches' or 'I have opened $80-90 \%$ of HB9's correctly though') as well as ratios (e.g. 'there was a 2:1 male to female ratio'), to rate women on attractiveness scales, and to provide detailed background information on specific events, such as the number of women talked to, the time and date the interaction took place, the age of the women, etc. Thus, the use of numerals to provide detailed background information not only adds a scientific air to the discourse but also objectifies the account of events. Numerals are an excellent means of establishing credibility and factuality via 'scrupulous detailing' (Dayter \& Rüdiger, 2014: 203; see also Drew, 1998 on defensive detailing and Dayter \& Rüdiger, 2016: 344 on the use of numerals as a powerful authenticating device). In other words, numbers make a report appear 'more real' and the teller of the story 'more objective'. The beginning of the following field report (see example 1) establishes it as factual, instead of a fictional account, by giving the relevant information in a list format including various numeric information on the exact date and time as well as a quantifiable goal, i.e. 'objective', for the day's activities.

\author{
Example (1) \\ Date: $\mathbf{4 / 2 0 / 1 4}$ \\ Place: Small City New England \\ Time: Approxiately [sic] 10:00 PM \\ Objective: Open and Hook Two Sets.
}

The most common use of numerals $(n=74)$ in the PUA field reports is to signal dates and times, or time frames, e.g. 'We talked about 10 minutes', '15 mins later dancing ended'. Another area where numerals crop up often is the infamous HB scale (one-fourth of all numbers; $n=51$ ). In this case, the numeral can be either used in combination with the acronym HB [hot babe], such as the first occurrence in example (2), or by itself as an elliptical reference to a woman, as demonstrated by the other occurrences of a numeral in (2) and (3).

(2) I talk with the dudes seated around me, making friends and adding to the vibe when Jay comes back with a HB10. To me 10s are rare, and she is definitely a $\mathbf{1 0}$.

(3) I managed to isolate the 7 from her friend $[\ldots]$.

\section{Abbreviations and acronyms}

The HB scale illustrates another scientification strategy, which is the use of acronyms and abbreviations. The development of acronyms in a discourse community is 'driven by the requirements for efficient communication exchange between experts' (Swales, 1990: 26) and their use ultimately leads to 'conciseness in specialized discourse' (Gotti, 2011: 32). It is not surprising then to imagine that scientists often use acronyms, as academia is not only an area where the gap between expert and layperson is particularly large, but it is also a domain where being an expert carries exceptional prestige. For example, Swales (1998: 74) described the talk in meetings of a university language testing centre as rich in acronyms and abbreviations. Research monographs often include whole lists of abbreviations, and some scholars lament the writing disease of 'acronymophilia' (Cheng, 1994; Isaacs \& Fitzgerald, 2000). However, we need to bear in mind that the use of jargon, including acronyms and abbreviation, is not unique to scientific contexts but is 
characteristic of any specialized discourse community, whether the community members are 'making widgets in a factory, teaching physics in a department, playing in an orchestra, or being active members of a local bicycle club' (Swales, 1998: 20). The PUAs have adopted this strategy of forming new words as well, and several acronyms (which are quite obscure to the uninitiated), in order to mark their way of communication (see Table 2).

Some PUA terminology occurs only as acronyms and never in full. For instance, in our data we only find $I O I$ but never an 'indicator(s) of interest' or 'indicator(s)'. Others, such as the members of the $X$-close group (X standing for either number, kiss, or fuck, depending on the results of the interaction), can occur either in abbreviated form $(n=5)$ or in full form $(n=8)$.

An online glossary of PUA acronyms (PUA Acronyms List, n.d.) lists as many as 162 items. Most of these acronyms, for example, $S M V$ for 'Sexual Market Value', FMAC for 'Find Meet Attract Close', $M L T R^{2}$ for 'Multiple Long Term Relationship Squared', do not occur in the field reports but, perhaps, are used by PUA gurus at training events to underline their guru status.

Example (4) demonstrates the use of the two most common acronyms (i.e. $H B$ and $I O I$ ) in the same paragraph. In this case, the acronym use goes hand in hand with a number of other PUA terminology (underlined) including quantification (2Set, $H B 8$ ), which together create the impression of an objective approach to dating. The choice of 'night club environment' instead of simply 'night club' adds further to the image of a technical perspective on approaching women: depending on the 'environment' and the interactants (here, two women, i.e. a $2 s e t$ ), specific strategies or techniques need to be employed (in this case a 'semi-direct social opener'). This implies that success merely depends on the correct choice of technique, and as such is a simple matter of training and experience. This over-analysis of social situations is one of the pillars of the PUA movement that finds expression in specific lexical choices.

(4) I was recently sarging in a night club environment and opened a 2Set with a social opener (semi direct). One of the girls responded really well (my HB8 target) and gave me IOIs immediately (she smiled and introduced herself by giving me a handshake and telling me her name). That made me a bit suspicious because I'm not the best looking guy and I wasn't peacocked at all.

\begin{tabular}{|c|c|c|c|}
\hline Term & & Frequency & Note \\
\hline HB & hot babe & 36 & used with or without numeral \\
\hline $\mathrm{IOI} / \mathrm{II}$ & indicator of interest & 11 & \\
\hline DHV & demonstration of high(er) value & 8 & verbal and nominal uses \\
\hline $\mathrm{A} 1$ & attraction phase $1 / 2 / 3$ & 7 & \\
\hline \multicolumn{4}{|l|}{$\mathrm{A} 2$} \\
\hline \multicolumn{4}{|l|}{ A3 } \\
\hline FR & field report & 6 & often in title of post \\
\hline PUA & pick-up artist & 6 & \\
\hline mPUA & master pick-up artist & & \\
\hline n-close & $\mathrm{n}=$ number & 5 & verbal and nominal uses \\
\hline k-close & $\mathrm{k}=\mathrm{kiss}$ & & \\
\hline f-klose & $\mathrm{f}=$ fuck & & \\
\hline AFC & average frustrated chump & 4 & \\
\hline AA & approach anxiety & 3 & \\
\hline UG & ugly girl & 2 & \\
\hline Total & & 88 & \\
\hline
\end{tabular}




\section{One word, many uses: Compounding and part-of-speech conversion}

PUA terms are characterized by a high constructional versatility. This means that a number of items consist of a basic lexical element which then combines with other optional elements (a process called compounding) and some items can be used in the capacity of different word classes (due to a process called conversion or zeroderivation). An example of compounding is the close-set, where close can combine with either $n$-, $k$-, or $f$ - or stand by itself as shown in example (5).

(5) I realized am good at opening to get the girls attention, but I never close them.

Some productive examples, demonstrated in (6) to (8), include the Hot Babe scale, set, and the fundamental PUA item game (noun).

(6) $H B$ (basic lexical element) + numerical value between 1-10 (optional element); e.g. $H B 8$, $H B 10, a H B$.

(7) numerical value or adjective (optional element) + set (basic lexical element); e.g. 2-set, 6-set, mixed set, mega set, the set.

(8) noun (optional element) + game (basic lexical element); e.g. day game, night game, text game, the game.

Game, from example (8), can also be used to illustrate the process of conversion as it sometimes functions as a verb (9) and sometimes as a noun (10).

(9) I feel I did not game her enough (verb).

(10) you can go out and get any girl you want when you're really good at the game (noun).

PUA neologisms are often not restricted to a single word-class. We find, to give some further examples, to neg (verb) and a neg (noun) meaning '(making a) negative comment about the woman one is interacting with', to close (verb) and $a$ close (noun), and to $\mathrm{DHV}$ (verb) and a $\mathrm{DHV}$ (noun) meaning 'demonstration of higher value'.

\section{Conclusion}

In their largely text-based community, pick-up artists play the imitation game. With surface markers such as PUA terms, they appeal to the members' desire to appear competent in some arcane field. Despite seeming impenetrable at first glance, the lingo is very easy to master since there is no real knowledge framework behind it, as would usually be the case with scientific terminology. The NLP paradigm provides an ideal reference point for the role-play since it offers just the right mix of folk psychology and miracle claims to appeal to the PUA audience.

By using the term-like words that we have described in this article, PUAs achieve a few things. Not only do they give the whole system a serious scientific air; they also draw a border between those who are 'in-the-know' and those who are not. Studies on code-switching between different languages or varieties of a language have shown that linguistic choices can be used to signal either a we-code, i.e. belonging to the in-group, or a theycode, i.e. belonging to the out-group (cf. Gumperz, 1977). Similarly, the use of PUA terminology by the aspiring pick-up artist signifies a desire to belong to or show belonging to the PUA speech community, the in-group. In the end, using PUA-specific terms, like 2-set, instead of more common ways of phrasing the same idea - for instance, two women - is a piece of identity-work communicating 'I am or want to be a pick-up artist. See how familiar I am with the ways of the PUA'.

With a huge number of followers around the globe, the movement is quite successful. Although rather unsavoury from a moral point of view (for example, a pick-up guru has been banned from entering the UK on the grounds that he promotes violence against women and his presence is 'not conducive to the public good' [BBC News, 19 November, 2014]), the PUA community presents a fascinating case of harnessing linguistic creativity for one's own purposes and makes an excellent dataset for the further study of persuasion.

\section{References}

Anthony, L. 2014. 'AntConc (Version 3.4.3).' Online at $<$ http://www.laurenceanthony.net/> (Accessed September 14, 2017).

BBC News. 2014. 'Julien Blanc: UK denies visa to "pick-up artist".' BBC News, November 19. Online at $<$ http://www. bbc.com/news/uk-30119100> (Accessed March 30, 2016).

Cheng, T. O. 1994. 'Acronymophilia.' BMJ, 309, 683.

Denes, A. 2011. 'Biology as consent: Problematizing the scientific approach to seducing women's bodies.' Women's Studies International Forum, 34, 411-19.

Dayter, D. \& Rüdiger, S. 2014. 'Speak your mind, but watch your mouth: Objectification strategies in negative references on CouchSurfing.' In: K. Bedijs, G. Held \& C. Maßß (eds.), Face Work and Social Media. Zürich; Berlin: LIT, pp. 193-212.

Dayter, D. \& Rüdiger, S. 2016. 'Reporting from the field: The narrative reconstruction of experience in pick-up artist online communities.' Open Linguistics, 2(1), 337-51.

Drew, P. 1998. 'Complaints about transgressions and misconduct.' Research on Language \& Social Interaction, 31(3-4), 295-325.

Glick, P. \& Fiske, S. 1996. 'The ambivalent sexism inventory: Differentiating hostile and benevolent sexism.' Journal of Personality and Social Psychology, 70(3), 491-512. 
Gotti, M. 2011. Investigating Specialized Discourse. $3^{\text {rd }}$ edn. Bern: Peter Lang.

Gumperz, J. 1977. 'The sociolinguistic significance of conversational code-switching.' RELC Journal, 8(2), 1-34.

Isaacs, D. \& Fitzgerald, D. 2000. 'Acronymophilia: An update.' Archives of Disease in Childhood, 83(6), 517-18.

Kuypers, J. 2009. 'Framing analysis.' In J. Kuypers (ed.), Rhetorical Criticism: Perspectives in Action. Plymouth: Lexington Press, pp. 181-204.

PUA Acronyms List. n.d. Online at <http://www.pualingo. com/pua-acronyms-list/> (Accessed February 28, 2018).

Rüdiger, S. \& Dayter, D. 2017. 'The ethics of researching unlikeable subjects.' Applied Linguistics Review, 8(2-3), 251-69.
Swales, J. M. 1990. Genre Analysis: English in Academic and Research Settings. Cambridge: Cambridge University Press.

Swales, J. M. 1998. Other Floors, Other Voices: A Textography of a Small University Building. Mahwah, NJ: Lawrence Erlbaum Associates.

Vrij, A. \& Lochun, S. 1997. 'Neuro-linguistic programming and the police: Worthwhile or not?' Journal of Police and Criminal Psychology, 12(1), 25-31.

Wilson, N. 2002. 'Commercializing mental health issues: Entertainment, advertising, and psychological advice.' In S. Lilienfeld, S. J. Lynn \& J. Lohr (eds.), Science and Pseudoscience in Clinical Psychology. New York: The Guilford Press, pp. 425-59. 